\title{
Self and Informant Memory Reports in FINGER : Associations with Two-Year Cognitive Change
}

\section{Vaskivuo, Laura}

2019

Vaskivuo , L , Hokkanen , L , Hänninen , T , Antikainen , R , Bäckman , L, Laatikainen , T , Paajanen , T , Stigsdotter-Neely , A , Strandberg , T , Tuomilehto , J , Soininen , H , Kivipelto , M \& Ngandu , T 2019 , ' Self and Informant Memory Reports in FINGER : Associations with Two-Year Cognitive Change ' , Journal of Alzheimer's Disease , vol. 71 , no. 3 , pp. 785-795 . https://doi.org/10.3233/JAD-190133

http://hdl.handle.net/10138/311830

https://doi.org/10.3233/JAD-190133

acceptedVersion

Downloaded from Helda, University of Helsinki institutional repository.

This is an electronic reprint of the original article.

This reprint may differ from the original in pagination and typographic detail.

Please cite the original version. 


\section{Self and Informant Memory Reports in FINGER: Associations with 2-year Cognitive Change}

Laura Vaskivuo ${ }^{1,2}$, Laura Hokkanen ${ }^{2}$, Tuomo Hänninen ${ }^{3}$, Riitta Antikainen ${ }^{4,5}$, Lars Bäckman ${ }^{6}$, Tiina Laatikainen, ${ }^{1,7,8}$, Teemu Paajanen ${ }^{9}$, Anna Stigsdotter-Neely ${ }^{10}$, Timo Strandberg ${ }^{4,11}$, Jaakko Tuomilehto ${ }^{1,12,13}$, Hilkka Soininen ${ }^{3,14}$, Miia Kivipelto ${ }^{1,6,14,15}$ and Tiia Ngandu ${ }^{1,15}$

${ }^{1}$ Public Health Promotion Unit, National Institute for Health and Welfare, Helsinki, Finland

${ }^{2}$ Department of Psychology and Logopedics, Faculty of Medicine, University of Helsinki, Finland ${ }^{3}$ Neurocenter/ Neurology, Kuopio University Hospital, Finland;

${ }^{4}$ University of Oulu, Center for Life Course health Research, Oulu, Finland

${ }^{5}$ Medical Research Center Oulu, Oulu University Hospital and Oulu City Hospital, Oulu, Finland

${ }^{6}$ Aging Research Center, Karolinska Institutet-Stockholm University, Stockholm, Sweden

${ }^{7}$ Institute of Public Health and Clinical Nutrition, University of Eastern Finland; Kuopio, Finland

${ }^{8}$ Hospital District of North Karelia, Joensuu, Finland

${ }^{9}$ Finnish Institute of Occupational Health, Helsinki, Finland

${ }^{10}$ Department of Psychology, Umeå University, Umeå, Sweden and Department of Social and Psychological Sciences, Karlstad university, Karlstad, Sweden.

${ }^{11}$ University of Helsinki, Clinicum, and Helsinki University Hospital, Helsinki, Finland

${ }^{12}$ South Ostrobothnia Central Hospital, Seinäjoki, Finland and Department of Public Health, University of Helsinki, Helsinki, Finland

${ }^{13}$ Dasman Diabetes Institute, Kuwait City, Kuwait, Danube University Kerms, Krems, Austria and Kind Abdulaziz University, Jeddah, Saudi Arabia

${ }^{14}$ Institute of Clinical Medicine/Neurology, University of Eastern Finland, Kuopio, Finland

${ }^{15}$ Karolinska Institutet Center for Alzheimer Research, Stockholm, Sweden 


\section{Abstract.}

Background: Subjective memory complaints (SMCs) may be the first sign of cognitive decline in aging.

Objective: To examine whether SMCs reported by oneself and informant predict cognitive change over 2 years among at-risk elderly people, and to determine the relationship of different types of SMCs (prospective and retrospective memory complaints) and change in cognitive function.

Methods: This investigation is part of the FINGER project, which is a multicenter randomized controlled trial aiming at preventing cognitive decline in cognitively healthy older adults with increased risk of dementia. A subsample of 303 control-group participants (aged 60-80 years) and their informants ( $n=261)$ rated the frequency of SMCs, using the Prospective and Retrospective Memory Questionnaire (PRMQ). Cognitive performance was measured at baseline and at 1- and 2-year follow-up visits using a neuropsychological test battery.

Results: Participants who reported more SMCs improved less in global cognition, executive function and memory during the subsequent 2 years in the fully-adjusted analyses. Self-reported RM problems predicted less improvement in all cognitive domains, whereas PM problems did not. Informantreported memory problems were not linked to subsequent change in cognition.

Conclusion: Our results indicate that self-reported SMCs, measured with PRMQ, predict future cognitive change in several cognitive domains. By contrast, reports by informants were not linked to changes in cognition. Among cognitively healthy at-risk elderly individuals, the persons themselves observe more easily problems relevant for their future cognitive trajectories than their informants.

Keywords: Aging, Cognition, Dementia, Memory 


\section{INTRODUCTION}

Memory impairments are often the first manifested symptoms of Alzheimer's disease (AD) [1]. Especially deficits in episodic memory, but also in other cognitive domains, including executive function and processing speed have been observed years before the clinical dementia diagnosis [1]. Assessing subjective memory complaints (SMCs), everyday memory concerns expressed by people, is one approach in attempting to detect early signs of degenerative dementing processes and enable early diagnosis. SMCs have been related to the development of cognitive decline and dementia [2-4] and to underlying neurophysiological changes even among persons with normal cognitive function $[5,6]$. However, associations have not been found in all studies [2-4,7] and SMCs have also been suggested to have limited utility for the very early identification of AD [8,9]. Further, SMCs may be inconsistently related to current cognitive functioning, but more strongly linked with future cognitive decline [10].

SMCs are very common among elderly individuals [7] and have been linked to a range of noncognitive factors, including depression [11], and to various demographic, clinical [7], and personality [12] characteristics. In addition, while memory self-awareness decreases during the progression of AD, it may show marked variability among persons with mild cognitive impairment [13].

Self- and informant-reported SMCs have been shown to diverge in prodromal stages of AD [14]. In clinical settings self-reports are often associated with actual cognitive test performance among healthy controls, but among patients with mild cognitive impairment informant reports are more often associated with cognition $[15,16]$. In a population-based study [2] both self-reported SMCs and informant reports predicted future dementia or $\mathrm{AD}$, independent of objective memory performance across 10-12 years follow-up time. In a non-demented clinical sample, informant complaints 
improved accuracy of the Mini Mental State Examination (MMSE) in predicting probable AD over 2 years but patient complaints did not [17]. A recent review suggested a higher risk of progression of cognitive impairment among individuals whose subjective complaints were corroborated by an informant [7].

Studies on SMCs have usually not assessed prospective (PM) and retrospective (RM) memory complaints separately. In short, PM is the ability to remember to perform a planned action or intention in the future, and RM refers to remembering the past events. Self-reported PM and RM complaints may offer important additional information with added discriminative power in identifying individuals at risk of future cognitive decline $[18,19]$. In our previous work both self-reported PM and RM complaints were linked to slower processing speed in cross-sectional analysis among cognitively healthy older persons at increased risk of dementia [20]. It has been suggested that PM failures may have greater impact on the lives of carers and, therefore, more likely to be reported [21]. In one study informant PM reports made an independent contribution to the prediction of AD over and above RM reports [22].

The objective of this study is to examine whether SMCs, including both PM and RM complaints, assessed both by participants and informants predict future cognitive change (over 2 years) among healthy at-risk elderly people.

\section{METHODS}

Study design 
The current study is part of the Finnish Geriatric Intervention Study to Prevent Cognitive Impairment and Disability (FINGER), (ClinicalTrials.gov identifier NCT01041989). The protocol and the main results of FINGER have been described earlier [23,24]. In brief, FINGER is a multi-center randomized controlled trial aiming to lower the risk of cognitive impairment in elderly persons at increased risk of cognitive decline. Participants received either an intensive multidomain intervention or regular health advice. The primary outcome was cognitive performance measured with the modified Neuropsychological Test Battery (NTB) [23]. FINGER has been approved by the Coordinating Ethics Committee of the Helsinki and Uusimaa Hospital District and written informed consent to perform this study was received.

\section{Participants}

Control group participants were included in this study, so that the role of SMCs in predicting cognitive change in a "non-intervention setting" can be assessed. Participants were 60-77 years of age at the beginning of the study. They were recruited from previous population-based, non-intervention surveys [25,26] that are well representative of the Finnish population [27]. Participants were prescreened using the Cardiovascular Risk Factors, Aging and Dementia (CAIDE) Dementia Risk Score, and those scoring at least 6 points (range $0-15$ points, based on age, sex, education, systolic blood pressure, body mass index, total cholesterol, and physical activity, indicating presence of some dementia risk factors) were invited to the screening visit. This group of persons scoring at least 6 points represents $84 \%$ of the population in this age group [27]. They were further screened with the Consortium to Establish a Registry for Alzheimer's Disease (CERAD) neuropsychological test battery. The Prospective and Retrospective Memory Questionnaire (PRMQ) was added to the study protocol after study onset, and thus, PRMQ data are available for the control-group participants who were included in the study after August 2010 (n=303). 
For inclusion, at least one of the following criteria had to be met: (1) Word List Memory Task learning score (10 words x 3) $\leq 19$ words; (2) Word List Recall $\leq 75 \%$; or (3) Mini-Mental State Examination (MMSE) $[28] \leq 26 / 30$ points. These criteria selected persons with cognitive performance at the mean level or slightly lower than expected for age according to Finnish population norms [29], but without substantial cognitive impairment. Nearly half of the screened participants fulfilled the inclusion criteria and were included in the study. The majority of the screened participants that were not included had CERAD test performance above the cut-off levels [27]. Exclusion criteria were conditions affecting safe engagement in the intervention (especially the exercise component): malignant diseases; major depression; dementia/substantial cognitive decline; MMSE $<20$; symptomatic cardiovascular disease; revascularization within 1 year; severe loss of vision, hearing, or communicative ability; conditions preventing cooperation as judged by study physicians; as well as coincident participation in any other intervention trial [27]. With these recruitment, inclusion/ exclusion criteria, the participants represent a group with an increased risk for dementia and room for improvement, and their mean cognitive performance was less than 0.5 SD below the average level of cognitively normal population $[27,30]$. In terms of neuropathology, the proportion of participants with brain amyloid accumulation is intermediate between healthy older adults and AD patients $\left({ }^{11} \mathrm{C}\right.$ Pittsburgh compound B -PET imaging conducted in a sub-sample of participants) [31].

During the study, 24 participants $(7.9 \%)$ in the current analytic sample discontinued. Main reasons were health related issues (12 participants), lack of time or motivation (4 participants) and unknown reasons (4 participants). Participant characteristics are reported in Table 1. 
Cognitive performance was measured at baseline and 1- and 2-year follow-ups, using a modified Neuropsychological Test Battery (NTB), known to be a reliable and sensitive measure of the mild cognitive changes typical for $\mathrm{AD}$ [32], expanded with additional tasks to detect executive dysfunction. Assessment was administered by trained study psychologists.

The NTB consisted of 14 tests from three different cognitive domains: The memory domain included Visual Paired Associates immediate and delayed; Logical Memory immediate and delayed from the Wechsler Memory Scale-Revised (WMS-III, WMS-R) [33]; and Word List Learning and Delayed Recall from the CERAD battery [29]. The executive-function domain included tests of Category Fluency [34], Digit Span [33], Concept Shifting (CST) [35] (condition C), Trail Making (TMT) [36] (shifting score B-A), and a shortened 40-stimulus version of the original Stroop test [37] (interference score 3-2). The processing-speed domain included Letter Digit Substitution (LDST) [38], Concept Shifting (condition A) and Stroop (condition 2).

Zero-skewness log-transformation was applied to skewed NTB components, and standardized z scores were calculated. NTB total score and domain scores for memory, executive functioning, and processing speed were obtained by averaging individual NTB component z scores. Z scores for tests at each timepoint were standardized to the baseline mean and SD of the total FINGER population $(n=1260)$. Because of missing values, the minimum number of necessary NTB components was set to $8 / 14$ for calculating the NTB total score, $3 / 5$ for executive functioning, $2 / 3$ for processing speed, and 3/6 for memory. A higher NTB score indicates better performance. 
Participants completed the PRMQ, and the informant version of PRMQ was given at the 6-month visit. PRMQ is a 16-item self-report measure of memory failures in everyday life [19]. Eight items inquire about PM and eight about RM. Each item has 5 response alternatives: Very often, quite often, sometimes, rarely or never. The PM questions enquire e.g. how often the participant decides to do something in a few minutes and then forgets to do it, or if he/she forgets appointments if not prompted by someone or by reminder such as calendar. The RM questions enquire e.g. does the participant forget something he/she was told a few minutes earlier, or if he/she repeats the same story to the same person on different occasions. The score ranges from 16 to 80. Higher scores indicate more SMCs. Both PRMQ and the informant version have acceptable reliability and validity $[18,19]$. Participants with missing values for any of the PRMQ items were excluded from analyses ( $\mathrm{n}=15$ for participant PRMQ and $n=42$ for informant PRMQ). In addition to continuous PRMQ values, also dichotomous variables (using median-value cutoffs) were used (PRMQ total $\geq 36$ and sub domains $\geq 18$ ).

\section{Other questionnaires and measures}

Participants completed at baseline visit several questionnaires inquiring about lifestyles, health status, mood, and quality of life. Depressive symptoms were assessed by the Zung Self-Rating Depression Scale [39], and quality of life was evaluated by the RAND-36 [40] Data on subjective health status were collected, using a 5-point Likert-scale (1=very good, 5=very poor). Self-reported frequency of leisure time physical activities causing sweating and breathlessness lasting at least 20 minutes at least twice a week was regarded as being physically active. Education was measured as number of years of schooling. Genomic DNA was extracted from venous blood samples with Chemagic MSM1 from PerkinElmer using magnetic beads. APOE genotyping was determined by polymerase chain reaction using TaqMan genotyping assays (Applied Biosystems (ABI), Foster City, CA, USA) for two single- 
nucleotide polymorphisms (rs429358 and rs7412) and an allelic discrimination method on the ABI 7500 platform [41].

\section{Statistical analyses}

All statistical analyses were performed using IBM SPSS Statistics version 22. Level of significance was set at $\mathrm{p}=.05$ in all analyses.

Descriptive statistics were used to characterize the study population. Linear mixed effects regression modeling was applied with Maximum likelihood estimation method. Change in cognitive test scores was modeled as a function of PRMQ or its subdomains, time and the PRMQ $\mathrm{x}$ time interaction. Variables considered as possible confounding factors were entered into models. These were included as fixed effects in linear mixed model. Specifically, we adjusted for age, sex, study site, education, and depression (model 1), and additionally for marital status, subjective health, physical activity and APOE $\varepsilon 4$ status (model 2). Covariates in the model 2 were not related to the outcome. Next, we investigated the covariate $\mathrm{x}$ time interactions by adding them one by one to model 1 . In the final model (model 3), we took into account the same covariates as in the model 1 and, additionally, covariate $\mathrm{x}$ time interactions for those that were significant in previous analytical steps (age $\mathrm{x}$ time and depression $\mathrm{x}$ time). Self-reported and informant-reported PRMQ scores were first analyzed separately, and in the last model simultaneously and with other covariates as in the model 1.

\section{RESULTS}

\section{Participant characteristics}


There were 303 participants (women=155; men=148). Participant characteristics and baseline cognitive performance are reported in Tables 1 and 2. Self-reported PRMQ data were available for 288 participants and informant-based PRMQ data for 261 participants. Mean score on total PRMQ reported by the participants was 36.0, and by the informants $30.4(\mathrm{p}<0.001$ for the difference between participant and informant ratings). No significant difference was found between PM and RM problems reported by participants $(\mathrm{p}>0.07)$. Informants reported more PM than RM problems $(\mathrm{p}=0.001)$.

Self-reported SMCs and change in neuropsychological performance

Overall, cognitive performance improved during two year follow-up $(\mathrm{p}<0.001)$. Mean change in NTB total score was 0.12 (SD 0.35). Reporting more memory complaints (higher PRMQ total) was related to less improvement in NTB total score and in memory even after full adjustments (Table 3). Higher PRMQ total score was also linked to reduced improvement in executive function, but the association was attenuated after adjustments. PRMQ total score was unrelated to change in processing speed.

PM complaints predicted less improvement in NTB total score and memory, although these associations were somewhat diluted with full adjustments. PM scores were not associated with change in either processing speed or executive function. RM complaints predicted less improvement in all cognitive domains, except processing speed.

Regarding dichotomous PRMQ variables, those with more reported PRMQ total or RM problems (PRMQ total $\geq 36 ; \mathrm{RM} \geq 18$ ) improved less in NTB total score compared with those who reported fewer memory problems (Figure 1). The mean difference between groups reporting more PRMQ problems compared with less PRMQ problems (group $\mathrm{x}$ time interaction) in change in NTB total 
score per year was $-0.062(95 \%$ CI -0.108 to -0.017$)$ for PRMQ total and -0.075 (-0.120 to -0.030$)$ for RM. Reporting more PM problems ( $\geq 18$ ) was not significantly associated with change in NTB total score; estimate -0.033 (-0.078 to 0.012$)$.

Informant-reported SMCs and change in neuropsychological performance

Informant reported data were received from participants' spouses (48.3\%), children (13.3\%), and significant others $(13.0 \%)$. Information on the relationship with the participant was missing for 25.3\%. More informant-reported SMCs (higher PRMQ total score) was linked to less improvement in executive function, but this effect fell short of significance after full adjustments (Table 3). Informant PRMQ total score was not associated with change in NTB total, processing speed or memory domains. Informant PM or RM complaints were unrelated to change in any cognitive domain after full adjustments. These patterns remained unchanged in sensitivity analyses within the group of spouses only.

Participant and informant PRMQ ratings analyzed simultaneously and change in neuropsychological performance

When both self and informant reports were adjusted for each other, self-reported PRMQ total score was associated with all other cognitive domains, except processing speed. Self-reported RM complaints predicted less improvement in all cognitive domains, and PM complaints were related to NTB total score and processing speed. Informant reports for PM complaints were associated with improvement in processing speed (Table 3).

\section{DISCUSSION}


The aim of this study was to examine whether self-reported or informant reported SMCs predict 2year cognitive change among healthy, but at-risk elderly people. The results show that having more self-reported SMCs, measured with the PRMQ predicts poorer development in NTB total and memory scores. Subjective RM problems, but not PM problems, predicted less improvement in NTB total, memory, and executive functions. Informant ratings in PRMQ total and PM and RM subscales were not associated with any cognitive domain after adjustments.

The question of whether self or informant reports are more predictive of future cognitive decline is complex, and depends on the time of the assessment. In contrast to some previous studies suggesting informant reports to be more predictive [2,17,42] when assessing self and informant reports simultaneously, our study found self-reports to be more accurate in predicting future cognitive change. Our older sample was cognitively healthy but at risk, whereas most previous studies were based on memory-clinic patients or persons with MCI. To our knowledge, this is the first study assessing both subjective PM and RM complaints simultaneously among both participants and their informants in relation to cognitive performance across several domains. Overall we were seeing an improvement in cognitive performance in our sample [23]. Such a pattern is quite common in longitudinal studies of cognitive aging with relatively short retest intervals and likely reflects placebo effects or practice effects of repeated cognitive testing. Also one other study has shown that cognitively normal individuals converting to MCI self-recognized decline earlier than informants [43]. In the current study, the changes noted by the informants (even if attenuated with full adjustments), were in fact linked to future changes in executive functions rather than to memory. When participant and informant reports were adjusted for each other, we observed that while participant-reported PM complaints were associated with less improvement in processing speed, informant-reported PM complaints were associated with more improvement. 
One previous study that investigated informant reports of PM and RM problems among participants with memory problems or early AD found that especially PM problems were linked to objective cognitive outcomes [22]. The present findings suggest that informant PM and RM reports are only weakly related to cognitive changes. Surprisingly, subjective PM problems were less associated with future cognitive change than RM problems; PM has been suggested to be more vulnerable than RM to changes in the early phase of $\mathrm{AD}[22,44]$. It has also been suggested that PM functions are especially important from an independent living point of view [45], and, therefore, more easily observed than RM problems. It could be that commonly used memory tests, as those included in our study, evaluate RM function more accurately than PM function. Self-reported PM and RM complaints have rarely been compared. One previous study suggested that self-reported RM but not PM complaints were helpful in differentiating elderly persons with subjective cognitive impairment and amnestic mild cognitive impairment, which is in line with the current results [46].

Decline in cognitive function, including both episodic memory and executive function may begin decades before diagnosis of dementia [47]. Even though the participants in our study did not face cognitive difficulties causing functional decline, their reports of memory problems were relevant for future changes in memory and executive function. Informant reports were somewhat linked to changes in executive function. Perhaps changes in executive functions can be earlier and more easily observed because of their relevance for everyday performance [48].

Affective factors in the individual or the informant or the quality of the relationship between the two might influence the subjective evaluations [49]. In addition to the depressive symptoms alone being an independent risk factor for dementia [50], these symptoms may affect the subjective experience of cognitive deficits, including memory problems [51]. In one study [52] cognitive and memory 
complaints were more closely associated with mood and general mental health than actual cognitive status. Toward this end, the associations observed between participant-reported SMCs and cognitive performance (NTB total, executive functions, and memory), and between informant- reported SMCs and cognition (executive functions), remained significant after adjusting for depressive symptoms.

This study has a number of strengths. The study population is drawn from earlier population-based studies, and with the inclusion criteria used, the population can be seen representative of the normal Finnish population with some risk factors for dementia, and cognitive functioning at the average level or slightly below the average of this age group [27]. Note that the study included only high-risk individuals, not participants already diagnosed with dementia. The richness of the data collected allowed adjusting for many possible confounding factors. In assessing neuropsychological performance, we used a comprehensive and standardized NTB comprising measurements of several key cognitive domains and a psychometrically validated [19] method for assessing SMCs. Finally, the drop-out rate was only $8 \%$ after 2 years.

The limitations include: the timing of the subjective memory assessment, as participants completed the PRMQ six months after the first neuropsychological testing. However, no major changes in memory functions or their subjective assessments are likely to have occurred during this time period. Because of the long preclinical stage before clinical dementia, it is possible that some participants might already have had some dementia-related brain changes. MCI diagnostics was not done and some of the participants might have fulfilled MCI criteria at baseline (depending on the criteria used). However, mean cognitive performance was less than 0.5 SD below the average level for the cognitively normal Finnish population [30]. The duration of the 2-year follow-up time was fairly short to track the progression of cognitive decline. However, studies with longer follow-up periods have reported similar results and shown SMCs to predict future diagnostic outcomes and later 
progression to $\mathrm{AD}[2,53]$. Due to a relatively small sample size our study may have had limited power to detect some moderate degree associations that may have existed. Although there are no validation studies or norms for the PRMQ in the Finnish population, the questionnaire is widely used and can be viewed as culturally neutral. No alternate versions of the cognitive tests were used which may have contributed to the magnitude of the observed improvement in cognitive performance over time.

In sum, our findings indicate that self-reported SMCs, measured with the PRMQ among cognitively healthy older adults at increased risk of cognitive decline, predict 2-year cognitive changes. The results are in line with previous findings that underscore the usefulness of subjective memory assessment in identifying individuals at risk of future cognitive impairment or eventually dementia [2]. Compared with informant reports, self-reported memory failures seem to be more sensitive indicators for predicting cognitive change in this relatively healthy population.

\section{ACKNOWLEDGMENTS}

This research was supported by grants from the Academy of Finland's Responding to Public Health Challenges Research Programme (SALVE), Academy of Finland grants 259615, 278457, 287490, 294061, 305810; La Carita Foundation, Juho Vainio Foundation, Novo Nordisk Foundation, Finnish Social Insurance Institution, Ministry of Education and Culture Research Grant, and EVO/VTR grants of University Hospitals of Kuopio, Oulu and Turku, Seinäjoki Central hospital and Oulu City

Hospital for FINGER project, Swedish Research Council; Alzheimer's Research \& Prevention Foundation USA; AXA Research Fund; the Sheika Salama Bint Hamdan Alahyan Foundation, Finnish Medical Foundation, Academy of Finland for Joint Program of Neurodegenerative Disorders - prevention (MIND-AD), an Alexander von Humboldt Research Award, Knut and Alice Wallenberg Foundation Sweden, Center for Innovative Medicine (CIMED) at Karolinska Institutet Sweden, 
Stiftelsen Stockholms sjukhem Sweden, Konung Gustaf V:s och Drottning Victorias Frimurarstiftelse Sweden, af Jochnick Foundation Sweden as well as personal grants from Finnish Brain foundation sr (LV).

The Funding sources had no involvement in study design, in the collection, analysis and interpretation of data, in the writing of the article or in the decision to submit the article for publication. The authors declare no conflict of interest.

\section{REFERENCES}

[1] Backman L, Jones S, Berger A, Laukka EJ, Small BJ (2005) Cognitive impairment in preclinical Alzheimer's disease: A meta-analysis. Neuropsychology 19, 520-531.

[2] Rönnlund M, Sundstrom A, Adolfsson R, Nilsson LG (2015). Self-Reported Memory Failures: Associations with Future Dementia in a Population-Based Study with Long-Term Follow-Up. J Am Geriatr Soc. 63, 1766-1773.

[3] Mitchell AJ, Beaumont H, Ferguson D, Yadegarfar M, Stubbs B (2014) Risk of dementia and mild cognitive impairment in older people with subjective memory complaints: meta-analysis. Acta Psychiatr.Scand. 130, 439-451.

[4] Jessen F, Amariglio RE, van Boxtel M, Breteler M, Ceccaldi M, Chételat G, Dubois B, Dufouil C, Ellis KA, van der Flier WM, Glodzik L, van Harten AC, de Leon MJ, McHugh P, Mielke MM, Molinuevo JL, Mosconi L, Osorio RS, Perrotin A, Petersen RC, Rabin LA, Rami L, Reisberg B, Rentz DM, Sachdev PS, de la Sayette V, Saykin AJ, Scheltens P, Shulman MB, Slavin MJ, Sperling RA, Stewart R, Uspenskaya O, Vellas B, Visser PJ, Wagner M, Subjective Cognitive Decline Initiative (SCD-I) Working Group.(2014) A conceptual framework for research on subjective cognitive decline in preclinical Alzheimer's disease. Alzheimers Dement 10:844-852.

[5] Saykin AJ, Wishart HA, Rabin LA, Santulli RB, Flashman LA, West JD, McHugh TL, Mamourian AC (2005) Older adults with cognitive complaints show brain atrophy similar to that of amnestic MCI. Neurology 12, 834-842.

[6] Hafkemeijer A, Altmann-Schneider I, Oleksik AM, van de Wiel L, Middelkoop HA, van Buchem MA, van der Grond J, Rombouts SA (2013) Increased functional connectivity and brain atrophy in elderly with subjective memory complaints. Brain Connect 3, 353-362.

[7] Mendonça MD, Alves L, Bugalho P (2016) From subjective cognitive complaints to dementia: Who is at risk?: A systematic review. Am J Alzheimers Dis Other Demen 31, 105-114. 
[8] Hollands S, Lim YY, Buckley R, Pietrzak RH, Snyder PJ, Ames D, Ellis KA, Harrington K, Lautenschlager N, Martins RN, Masters CL, Villemagne VL, Rowe CC, Maruff P (2015) Amyloid-beta related memory decline is not associated with subjective or informant rated cognitive impairment in healthy adults. J Alzheimers Dis 43, 677-686.

[9] Burmester B, Leathem J, Merrick P (2016) Subjective cognitive complaints and objective cognitive function in aging: A systematic review and meta-analysis of recent cross-sectional findings. Neuropsychol Rev 26, 376-393.

[10] Reid LM, MacLullich AMJ. (2006) Subjective Memory Complaints and Cognitive Impairment in Older People. Dement Geriatric Cogn Disord 22, 471-485.

[11] Lehrner J, Moser D, Klug S, Gleiß A, Auff E, Dal-Bianco P, Pusswald G (2014) Subjective memory complaints, depressive symptoms and cognition in patients attending a memory outpatient clinic. Int Psychogeriatr, 26, 463-473.

[12] Studer J, Donati A, Popp J, von Gunten A (2014) Subjective cognitive decline in patients with mild cognitive impairment and healthy older adults: association with personality traits. Geriatr Gerontol Int 14, 589-595.

[13] Vannini P, Amariglio R, Hanseeuw B, Johnson KA, McLaren DG, Chhatwal J, Pascual-Leone A, Rentz D, Sperling RA (2017) Memory self-awareness in the preclinical and prodromal stages of Alzheimer's disease. Neuropsychologia, 99, 343-349.

[14] Buckley R, Saling M, Ellis K, Rowe C, Maruff P, Macaulay LS, Martins R, Masters C, Savage G, Rainey-Smith S, Rembach A, Ames D (2015) Self and informant memory concerns align in healthy memory complainers and in early stages of mild cognitive impairment but separate with increasing cognitive impairment. Age Ageing, 44, 1012-1019.

[15] Edmonds EC, Delano-Wood L, Galasko DR, Salmon DP, Bondi MW, Alzheimer's Disease Neuroimaging Initiative (2014) Subjective cognitive complaints contribute to misdiagnosis of mild cognitive impairment. J Int Neuropsychol Soc.20, 836-847.

[16] Buelow M, Tremont G, Frakey L Grace J, Ott BR (2014) Utility of the cognitive difficulties scale and association with objective test performance. Am J Alzheimer's Dis Other Demen 29, 755764.

[17] Tierney MC. Herrmann N, Geslani DM, Szalai JP (2003) Contribution of informant and patient ratings to the accuracy of the mini-mental state examination in predicting probable Alzheimer's disease. J Am Geriatr Soc 51, 813-818.

[18] Crawford JR, Henry JD, Ward AL, Blake J (2006) The prospective and retrospective memory questionnaire (PRMQ): Latent structure, normative data and discrepancy analysis for proxy-ratings. Br J of Clin Psychol, 45, 83-104.

[19] Crawford JR, Smith G, Maylor EA, Della Sala S, Logie RH (2003) The Prospective and Retrospective Memory Questionnaire (PRMQ): Normative data and latent structure in a large nonclinical sample. Memory 11, 261-275. 
[20] Vaskivuo L, Hokkanen L, Hänninen T, Antikainen R, Bäckman L, Laatikainen T, Paajanen T, Stigsdotter-Neely A, Strandberg T, Tuomilehto J, Soininen H, Kivipelto M, Ngandu T (2018) Associations between Prospective and Retrospective Subjective Memory Complaints and Neuropsychological Performance in Older Adults : The Finger Study. J Int Neuropsychol Soc. 24, 1099-1109.

[21] Smith G. Della Sala S, Logie RH, Maylor EA (2000) Prospective and retrospective memory in normal ageing and dementia: A questionnaire study. Memory 8, 311-321.

[22] Hsu Y (2014) The Clinical Utility of Informants' Appraisals on Prospective and Retrospective Memory in Patients with Early Alzheimer's Disease. PLoS ONE 9, 1-8.

[23] Ngandu T, Lehtisalo J, Solomon A, Levälahti E, Ahtiluoto S, Antikainen R, Bäckman L, Hänninen T, Jula A, Laatikainen T, Lindström J, Mangialasche F, Paajanen T, Pajala S, Peltonen M, Rauramaa R, Stigsdotter-Neely A' Strandberg T, Tuomilehto J, Soininen H, Kivipelto M (2015) A 2 year multidomain intervention of diet, exercise, cognitive training, and vascular risk monitoring versus control to prevent cognitive decline in at-risk elderly people (FINGER): a randomised controlled trial. Lancet 385, 2255-2263.

[24] Kivipelto M, Solomon A, Ahtiluoto S, Ngandu T, Lehtisalo J, Antikainen R, Bäckman L, Hänninen T, Jula A, Laatikainen T, Lindström J, Mangialasche F, Nissinen A, Paajanen T, Pajala S, Peltonen M, Rauramaa R, Stigsdotter-Neely A, Strandberg T, Tuomilehto J, Soininen H (2013) The Finnish Geriatric Intervention Study to Prevent Cognitive Impairment and Disability (FINGER): study design and progress. Alzheimers Dement 9, 657-665.

[25] Vartiainen E, Laatikainen T, Peltonen M, Juolevi A, Männistö S, Sundvall J, Jousilahti P, Salomaa V, Valsta L, Puska P (2010) Thirty-five-year trends in cardiovascular risk factors in Finland. Int J Epidemiol 39, 504-518.

[26] Saaristo T, Peltonen M, Keinänen-Kiukaanniemi S, Vanhala M, Saltevo J, Niskanen L, Oksa H, Korpi-Hyövälti E, Tuomilehto J; FIN-D2D Study Group. (2007) National type 2 diabetes prevention programme in Finland FIN-D2D. International journal of circumpolar health 66, 101112.

[27] Ngandu T, Lehtisalo J, Levälahti E, Laatikainen T, Lindström J, Peltonen M, Solomon A, Ahtiluoto S, Antikainen R, Hänninen T, Jula A, Mangialasche F, Paajanen T, Pajala S, Rauramaa R, Strandberg T, Tuomilehto J, Soininen H, Kivipelto M (2014) Recruitment and Baseline Characteristics of Participants in the Finnish Geriatric Intervention Study to Prevent Cognitive Impairment and Disability (FINGER)-A Randomized Controlled Lifestyle Trial. International Journal of Environmental Research And Public Health 11, 9345-9360.

[28] Folstein MF, Folstein SE, McHugh PR (1975) "Mini-mental state". A practicalmethod for grading the cognitivestate of patients for the clinician. Journal of psychiatric research 12, 189-198.

[29] Pulliainen V, Hänninen T, Hokkanen L, Tervo S, Vanhanen M, Pirttilä T, Soininen H (2007) Norms for use of the CERAD test battery in Finland. Suomalainen lääkärilehti (Finnish Medical Journal) 62, 1235-1241 (in Finnish).

[30] Hanninen T, Pulliainen V, Sotaniemi M, Hokkanen L, Salo J., Hietanen M, Pirttilä T, Pöyhänen M, Juva K, Remes A, Erkinjuntti T. (2010). Early detection of cognitive changes in memory diseases: 
new cut-off scores for the Finnish version of CERAD neuropsychological battery. Duodecim, 126, 2013-2021 (in Finnish).

[31] Kemppainen N, Johansson J, Teuho J, Parkkola R, Joutsa J, Ngandu T, Solomon A, Stephen R, Liu Y, Hänninen T, Paajanen T, Laatikainen T, Soininen H, Jula A, Rokka J, Rissanen E, Vahlberg T, Peltoniemi J, Kivipelto M, Rinne JO (2018) Brain amyloid load and its associations with cognition and vascular risk factors in FINGER Study. Neurology 90, 206-213.

[32] Harrison J, Minassian SL, Jenkins, L Black RS, Koller M, Grundman M (2007) A neuropsychological test battery for use in Alzheimer disease clinical trials. Archives of Neurology 64, 1323-1329.

[33] Wechsler D editor. WMS-III-Administration and Scoring Manual. Psychological Corporation Ltd ed. London, UK: Psychological Corporation Ltd; 1998.

[34] Morris JC, Heyman A, Mohs RC, Hughes JP, van Belle G, Fillenbaum G, Mellits ED, Clark C (1988) Consortium to establish a registry for alzheimer's disease (CERAD) clinical and neuropsychological assessment of alzheimer's disease. Psychopharmacol Bull 24, 641-652.

[35] Van der Elst W, Van Boxtel MP, Van Breukelen GJ, Jolles J (2006) The concept shifting test: Adult normative data. Psychological Assessment 18, 424-432.

[36] Reitan R. (1959) Validity of the Trail Making Test as an indicator of organic brain damage. Percept.Mot.Skills 8, 271-276.

[37] Golden C editor. Stroop Color and Word Test: A Manual for Clinical and Experimental Uses. Chicago, IL, USA: Skoelting; 1978.

[38] van Der Elst W, van Boxtel MP, van Breukelen GJ, Jolles J (2006) The Letter Digit Substitution Test: Normative data for 1,858 healthy participants aged 24-81 from the Maastricht Aging Study (MAAS): Influence of age, education, and sex. J Clin Exp Neuropsychol 28, 998-1009.

[39] Zung A (1965) A self-rating depression scale. Arch Gen Psychiatry 12, 63-70.

[40] Aalto AM, Aro AR, Teperi J (1999) RAND-36 as a measure of Health-Related Quality of Life. Reliability, construct validity, and reference values in the Finnish general population. Stakes, Research Reports: Helsinki, Finland 101.

[41] De La Vega F, Lazaruk K, Rhodes M, Wenz MH (2005) Assessment of two flexible and compatible SNP genotyping platforms: TaqMan ${ }^{\circledR}$ SNP Genotyping Assays and the SNPlex ${ }^{\mathrm{TM}}$ Genotyping System. Mutat Res 573, 111-135.

[42] Carr DB, Gray S, Baty J, Morris J (2000) The value of informant versus individual's complaints of memory impairment in early dementia. Neurology 55, 1724-1726.

[43] Caselli RJ, Chen K, Locke DE, Lee W, Roontiva A, Bandy D, Fleisher AS, Reiman EM (2014) Subjective cognitive decline: self andinformant comparisons. Alzheimers Dement 10, 93-98.

[44] Crumley JJ, Stetler CA, Horhota M. (2014) Examining the Relationship Between Subjective and Objective Memory Performance in Older Adults: A Meta-Analysis. Psychol Aging 29, 250-263. 
[45] Salthouse TA, Berish DE, Siedlecki KL (2004) Construct validity and age sensitivity of prospective memory. Mem Cognit 32, 1133-1148.

[46] Ryu SY, Lee SB, Kim TW, Lee TJ (2016) Memory complaints in subjective cognitive impairment, amnestic mild cognitive impairment and mild Alzheimer's disease. Acta Neurol Belg 116, 535-541.

[47] Mortamais M, Ash JA, Harrison J, Kaye J, Kramer J, Randolph C, Pose C, Albala B, Ropacki M, Ritchie CW, Ritchie K (2017) Detecting cognitive changes in preclinicalAlzheimer's disease: A review of its feasibility. Alzheimers Dement 13, 468-492.

[48] Mäntyla T (2003) Assessing absentmindedness: Prospective memory complaint and impairment in middle-aged adults. Mem Cognit 31, 15-25.

[49] Elfgren C. Gustafson L. Vestberg S (2010) Subjective memory complaints, neuropsychological performance and psychiatric variables in memory clinic attendees: A 3-year follow-up study. Arch Gerontol Geriatr 51, e110-e114.

[50] Ownby R, Crocco E, Acevedo A, John V, Loewenstein D (2006) Depression and risk for Alzheimer disease: systematic review, meta-analysis, and metaregression analysis. Arch Gen Psychiatry 63, 530-538.

[51] Heser K, Tebarth F, Wiese B, Eisele M, Bickel H, Köhler M, Mösch E, Weyerer S, Werle J, König HH, Leicht H, Pentzek M, Fuchs A, Riedel-Heller SG, Luppa M, Prokein J, Scherer M, Maier W, Wagner M; Age CoDe Study Group (2013) Age of major depression onset, depressive symptoms, and risk for subsequent dementia: Results of the german study on ageing, cognition and dementia in primary care patients (AgeCode). Psychol Med 43, 1597-1610.

[52] Weaver C, Collie A, Masters C, Maruff P (2008) The nature of cognitive complaints in healthy older adults with and without objective memory decline. J Clin Exp Neuropsychol 30, 245-257.

[53] Jonker C, Geerlings MI, Schmand B (2000) Are memory complaints predictive for dementia? A review of clinical and population-based studies. Int J Geriatr Psychiatry 15, 983-991. 
Table 1. Baseline characteristics of the participants (mean, standard deviation (SD) or \%) and cognitive performance in different domains during study

\begin{tabular}{|c|c|c|c|c|}
\hline \multicolumn{2}{|c|}{ Characteristic } & $N$ & mean / \% & SD \\
\hline \multicolumn{5}{|c|}{ Baseline characteristics } \\
\hline \multicolumn{2}{|c|}{ Age (years) } & 303 & 70.0 & 4.9 \\
\hline \multicolumn{2}{|c|}{$\operatorname{Sex}(\%$ men/ women $)$} & 303 & $48.8 / 51.2$ & \\
\hline \multicolumn{2}{|c|}{ Education (years) } & 303 & 10.2 & 3.4 \\
\hline \multicolumn{2}{|c|}{ Married / cohabiting (\%) } & 303 & 71.6 & \\
\hline \multicolumn{2}{|c|}{ Zung self-rating depression scale* } & 294 & 35.8 & 7.6 \\
\hline \multicolumn{2}{|c|}{ Subjective health (quite good or very good, \%) } & 302 & 58.6 & \\
\hline \multicolumn{2}{|c|}{ Physically active (\%) } & 300 & 70.6 & \\
\hline \multicolumn{5}{|c|}{ PRMQ ratings / subscales } \\
\hline & Participants total* & 288 & 36.0 & 7.8 \\
\hline & prospective* & 298 & 17.9 & 4.2 \\
\hline & retrospective* & 293 & 18.1 & 4.2 \\
\hline & \multirow{3}{*}{$\begin{array}{l}\text { total* } \\
\text { prospective* } \\
\text { retrospective* }\end{array}$} & 261 & 30.4 & 9.9 \\
\hline & & 272 & 15.5 & 5.3 \\
\hline & & 266 & 15.0 & 5.0 \\
\hline \multicolumn{2}{|c|}{ Mini-Mental State Examination (MMSE) } & 303 & 27.0 & 2.0 \\
\hline \multirow[t]{4}{*}{ Study site } & Helsinki $\quad(\mathrm{n}, \%)$ & 37 & 12.2 & \\
\hline & Vantaa & 44 & 14.5 & \\
\hline & Kuopio & 107 & 35.3 & \\
\hline & Turku $\quad(\mathrm{n}, \%)$ & 115 & 38.0 & \\
\hline \multicolumn{2}{|c|}{ Apoliproprotein E $\varepsilon 4$ carriers (n, \%) } & 285 & 34.7 & \\
\hline \multicolumn{5}{|c|}{ Cognitive performance during study** } \\
\hline \multirow[t]{4}{*}{ Baseline } & NTB total & 302 & 0.0 & 0.6 \\
\hline & Processing speed & 302 & 0.0 & 0.9 \\
\hline & Executive functions & 302 & 0.0 & 0.7 \\
\hline & Memory & 302 & 0.0 & 0.6 \\
\hline \multirow[t]{4}{*}{12 months } & NTB total & 295 & 0.1 & 0.7 \\
\hline & Processing speed & 295 & 0.1 & 0.9 \\
\hline & Executive functions & 295 & 0.0 & 0.7 \\
\hline & Memory & 295 & 0.2 & 0.8 \\
\hline \multirow[t]{4}{*}{24 months } & NTB total & 277 & 0.2 & 0.7 \\
\hline & Processing speed & 277 & 0.0 & 0.9 \\
\hline & Executive functions & 276 & 0.1 & 0.7 \\
\hline & Memory & 278 & 0.3 & 0.8 \\
\hline
\end{tabular}

PRMQ=Prospective and Retrospective Memory Questionnaire; NTB=Neuropsychological test battery.

*Range for possible scores: Zung scale (20-80); PRMQ total (16-80); PRMQ prospective score (840), PRMQ retrospective score (8-40); MMSE (0-30). Higher scores on PRMQ indicate presence of more complaints.

**Higher scores on NTB total and domain scores indicate better cognitive performance. 
Table 2. Cognitive performance at baseline (mean, standard deviation (SD))

\begin{tabular}{llll}
\hline Neuropsychological test & N & Mean & SD \\
\hline Memory & & & \\
WMS-R Logical Memory (immediate) & 301 & 11.0 & 3.4 \\
WMS-R Logical Memory (delayed) & 301 & 9.4 & 3.6 \\
CERAD Word List Learning & 303 & 18.3 & 3.2 \\
CERAD Word List Recall & 302 & 5.5 & 1.6 \\
WMS-R Visual Paired Associates (immediate) & 297 & 9.6 & 3.6 \\
WMS-R Visual Paired Associates (delayed) & 296 & 3.5 & 1.8 \\
Executive Function & & & \\
CERAD Category Fluency & 303 & 22.4 & 5.5 \\
WMS-R Digit Span (total) & 301 & 11.3 & 2.8 \\
CST (condition C) * & 293 & 65.9 & 39.0 \\
TMT shifting score (B-A) * & 292 & 103.7 & 63.3 \\
Stroop test interference score (3-2) * & 301 & 35.0 & 18.4 \\
Processing speed & & & \\
LDST & 300 & 21.8 & 5.8 \\
CST (condition A) * & 301 & 32.9 & 10.1 \\
Stroop test (condition 2) * & 301 & 28.9 & 6.5 \\
\hline
\end{tabular}

* Timed task where lower scores indicate faster performance/better test results. In other tasks, higher numbers indicates better results. WMS-R=Wechsler Memory Scale-Revised,

CERAD $=$ Consortium to Establish a Registry for Alzheimer's Disease, CST=Concept Shifting Test, TMT=Trail Making Test, LDST=Letter Digit Substitution Test 
Table 3. The association between self-reported and informant-reported prospective and retrospective memory complaints (measured with Prospective and Retrospective Memory Questionnaire, PRMQ) and change in cognitive function during 2 years. Results are from mixed linear models (estimates of PRMQ effect per year and $\mathrm{p}$ values).

\begin{tabular}{|c|c|c|c|c|c|c|}
\hline & \multicolumn{3}{|c|}{ Participants } & \multicolumn{3}{|c|}{ Informants } \\
\hline & MODEL 1 & MODEL 2 & MODEL 3 & MODEL 1 & MODEL 2 & MODEL 3 \\
\hline & $\begin{array}{c}\text { Estimate of } \\
\text { PRMQ for change } \\
\text { in cognition per } \\
\text { year (p-value) }\end{array}$ & $\begin{array}{c}\text { Estimate of } \\
\text { PRMQ for change } \\
\text { in cognition per } \\
\text { year (p-value) }\end{array}$ & $\begin{array}{l}\text { Estimate of } \\
\text { PRMQ for change } \\
\text { in cognition per } \\
\text { year (p-value) }\end{array}$ & $\begin{array}{c}\text { Estimate of PRMQ } \\
\text { for change in } \\
\text { cognition per year } \\
(p \text {-value })\end{array}$ & $\begin{array}{l}\text { Estimate of PRMQ } \\
\text { for change in } \\
\text { cognition per year } \\
\text { (p-value) }\end{array}$ & $\begin{array}{c}\text { Estimate of PRMQ } \\
\text { for change in } \\
\text { cognition per year } \\
\text { (p-value) }\end{array}$ \\
\hline \multicolumn{7}{|l|}{ Total PRMQ } \\
\hline NTB total & $-0.004(\mathbf{0 . 0 0 1})$ & $-0.004(\mathbf{0 . 0 0 2})$ & $-0.003(\mathbf{0 . 0 1 5})$ & $-0.002(0.082)$ & $-0.002(0.073)$ & $-0.001(0.459)$ \\
\hline Processing speed & $-0.003(0.109)$ & $-0.003(0.093)$ & $-0.002(0.253)$ & $0.001(0.446)$ & $0.001(0.436)$ & $0.002(0.172)$ \\
\hline Executive functions & $-0.003(\mathbf{0 . 0 3 7})$ & $-0.003(\mathbf{0 . 0 4 9})$ & $-0.003(0.101)$ & $-0.003(\mathbf{0 . 0 1 9})$ & $-0.003(\mathbf{0 . 0 2 5})$ & $-0.002(0.071)$ \\
\hline Memory & $-0.006(\mathbf{0 . 0 0 5})$ & $-0.006(\mathbf{0 . 0 1 1})$ & $-0.005(\mathbf{0 . 0 4 7 )}$ & $-0.003(0.106)$ & $-0.003(0.092)$ & $-0.001(0.443)$ \\
\hline \multicolumn{7}{|l|}{ Prospective memory } \\
\hline NTB total & $-0.006(\mathbf{0 . 0 2 0})$ & $-0.005(\mathbf{0 . 0 3 4})$ & $-0.004(0.117)$ & $-0.003(0.168)$ & $-0.003(0.159)$ & $-0.001(0.649)$ \\
\hline Processing speed & $-0.004(0.234)$ & $-0.004(0.245)$ & $-0.003(0.411)$ & $0.004(0.181)$ & $0.004(0.200)$ & $0.005(0.051)$ \\
\hline Executive functions & $-0.004(0.190)$ & $-0.003(0.244)$ & $-0.003(0.367)$ & $-0.005(\mathbf{0 . 0 4 2})$ & $-0.004(0.053)$ & $-0.004(0.115)$ \\
\hline Memory & $-0.008(\mathbf{0 . 0 4 5})$ & $-0.008(0.073)$ & $-0.006(0.198)$ & $-0.005(0.150)$ & $-0.005(0.141)$ & $-0.003(0.460)$ \\
\hline \multicolumn{7}{|c|}{ Retrospective memory } \\
\hline NTB total & $-0.009(<\mathbf{0 . 0 0 1})$ & $-0.009(<\mathbf{0 . 0 0 1})$ & $-0.007(\mathbf{0 . 0 0 5})$ & $-0.004(0.075)$ & $-0.004(0.062)$ & $-0.002(0.398)$ \\
\hline Processing speed & $-0.006(0.062)$ & $-0.006(\mathbf{0 . 0 4 0})$ & $-0.004(0.182)$ & $0.001(0.776)$ & $0.004(0.762)$ & $0.002(0.408)$ \\
\hline Executive functions & $-0.007(\mathbf{0 . 0 1 3})$ & $-0.007(\mathbf{0 . 0 1 6})$ & $-0.006(\mathbf{0 . 0 4 8})$ & $-0.005(\mathbf{0 . 0 2 8})$ & $-0.005(\mathbf{0 . 0 3 7})$ & $-0.004(0.094)$ \\
\hline Memory & $-0.013(\mathbf{0 . 0 0 2})$ & $-0.012(\mathbf{0 . 0 0 4 )}$ & $-0.010(\mathbf{0 . 0 2 6})$ & $-0.006(0.107)$ & $-0.007(0.080)$ & $-0.003(0.419)$ \\
\hline
\end{tabular}

PRMQ=Prospective and Retrospective memory questionnaire

Model 1. Adjusted for age, sex, study site, education and depression.

Model 2. Adjusted for age, sex, study site, education, depression, marital status, subjective health, physical activity and ApoE4 allele.

Model 3. Adjusted for age, sex, study site, education and depression and interactions with time and age and depression.

Higher scores on PRMQ indicate presence of more complaints. Higher scores on cognitive outcomes indicate better cognitive performance.

Significant effects are in bold typeface. 
Table 4. The association between self-reported and informant-reported prospective and retrospective memory complaints (measured with Prospective and Retrospective Memory Questionnaire, PRMQ) and change in cognitive function during 2 years. Participant and informant repots are adjusted for each other. Results are from mixed linear models (estimates of PRMQ effect per year and $\mathrm{p}$ values).

\begin{tabular}{|c|c|c|}
\hline Reports & Participants & Informants \\
\hline & $\begin{array}{l}\text { Estimate of } \\
\text { PRMQ for } \\
\text { change in } \\
\text { cognition per } \\
\text { year (p-value) }\end{array}$ & $\begin{array}{l}\text { Estimate of } \\
\text { PRMQ for } \\
\text { change in } \\
\text { cognition per } \\
\text { year (p-value) }\end{array}$ \\
\hline \multicolumn{3}{|l|}{ Total PRMQ } \\
\hline NTB total & $-0.005(\mathbf{0 . 0 0 1})$ & $-0.000(0.745)$ \\
\hline Processing speed & $-0.005(\mathbf{0 . 0 1 0})$ & $0.003(0.057)$ \\
\hline Executive functions & $-0.003(0.110)$ & $-0.002(0.119)$ \\
\hline Memory & $-0.006(\mathbf{0 . 0 1 3})$ & $-0.001(0.579)$ \\
\hline \multicolumn{3}{|l|}{ Prospective memory } \\
\hline NTB total & $-0.006(\mathbf{0 . 0 2 1})$ & $-0.001(0.733)$ \\
\hline Processing speed & $-0.008(\mathbf{0 . 0 3 6})$ & $0.006(\mathbf{0 . 0 3 2})$ \\
\hline Executive functions & $-0.003(0.295)$ & $-0.004(0.145)$ \\
\hline Memory & $-0.008(0.098)$ & $-0.003(0.444)$ \\
\hline \multicolumn{3}{|l|}{ Retrospective memory } \\
\hline NTB total & $-0.010(<\mathbf{0 . 0 0 1})$ & $-0.001(0.712)$ \\
\hline Processing speed & $-0.010(\mathbf{0 . 0 0 7})$ & $0.004(0.155)$ \\
\hline Executive functions & $-0.006(\mathbf{0 . 0 3 8})$ & $-0.004(0.163)$ \\
\hline Memory & $-0.013(\mathbf{0 . 0 0 5})$ & $-0.002(0.580)$ \\
\hline
\end{tabular}

PRMQ=Prospective and Retrospective memory questionnaire

Model adjusted for age, sex, study site, education and depression, and self and informant reports are entered simultaneously.

Higher scores on PRMQ indicate presence of more complaints.

Higher scores on cognitive outcomes indicate better cognitive performance.

Significant effects are in bold typeface. 
Figure 1. Cognitive changes during 2 year follow-up time as a function of subjective memory assessment; part A for total PRMQ; part B for prospective memory; and part C for retrospective memory. The figure shows estimated mean change in cognitive performance from baseline through 12 and 24 months (higher scores indicate better performance). Error bars are standard errors around the means. Mixed-model repeated-measures analyses were used to assess between-group differences (higher/lower subjective memory complaints ) in changes from baseline to 24 months based on data from participants with at least one postbaseline measurement. Low and high refer to the amount of reported subjective memory complaints below or above the median level (using cutoffs: PRMQ total $\geq 36$ and sub domains $\geq 18$ )

A:

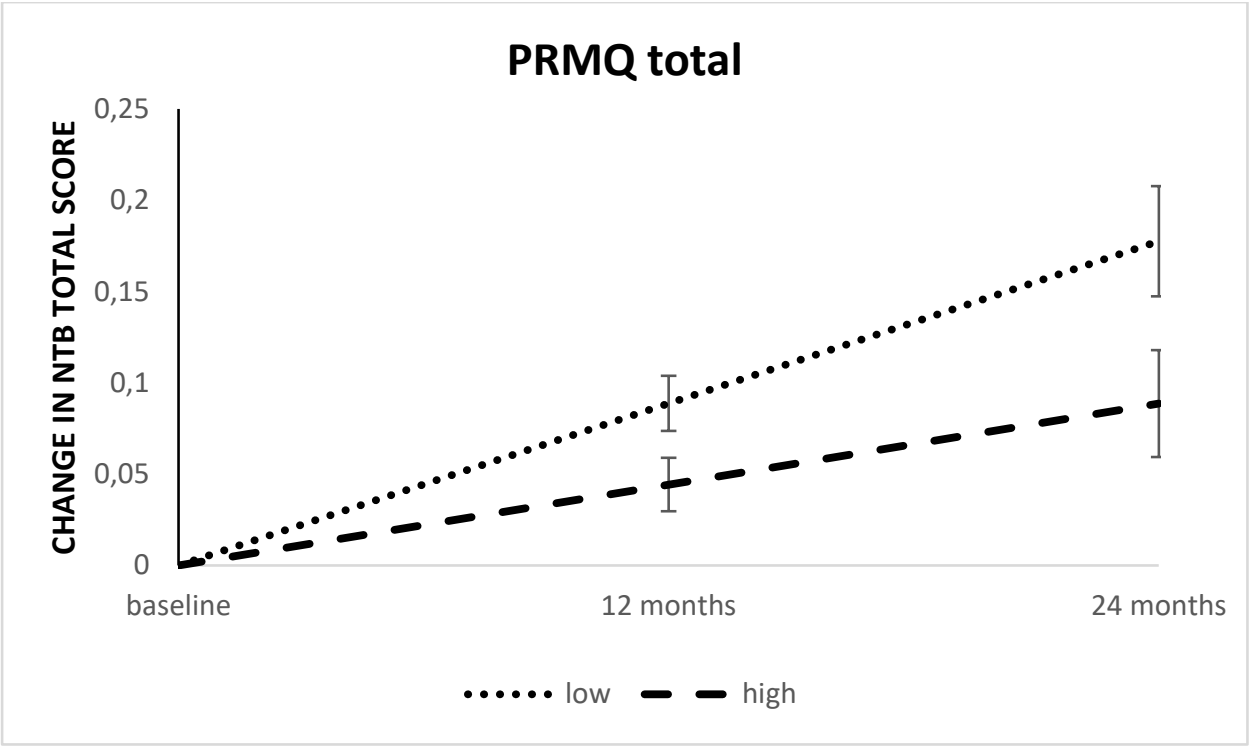

B:

retrospective memory

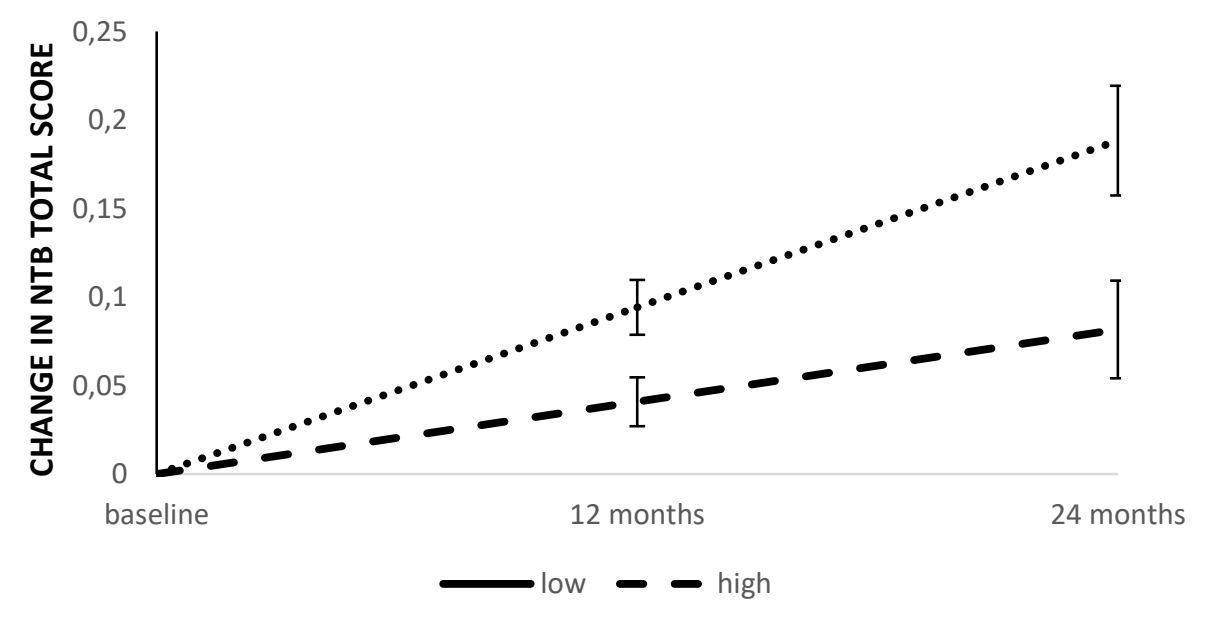


C:

\section{prospective memory}

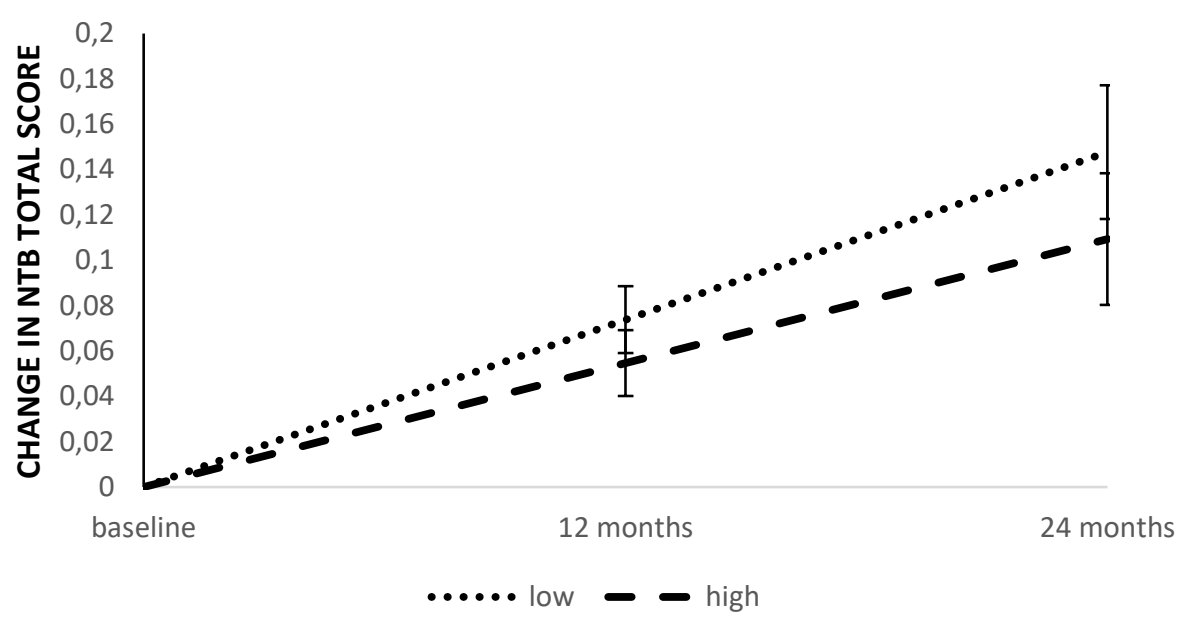

